\title{
THE
}

\section{Preindustrial and Postwar Economic Development: Is There a Link?}

John P. Burkett

University of Rhode Island, burkett@uri.edu

Catherine Humblet

Louis Putterman

Follow this and additional works at: https://digitalcommons.uri.edu/ecn_facpubs

Terms of Use

All rights reserved under copyright.

\section{Citation/Publisher Attribution}

Burkett, John P., Catherine Humblet, and Louis Putterman. 1999. "Preindustrial and Postwar Economic Development: Is There a Link?." Economic Development and Cultural Change 47, no. 3 (April): 471-495. http://dx.doi.org/10.1086/452416

Available at http://www.jstor.org/stable/10.1086/452416

This Article is brought to you for free and open access by the Economics at DigitalCommons@URI. It has been accepted for inclusion in Economics Faculty Publications by an authorized administrator of DigitalCommons@URI. For more information, please contact digitalcommons-group@uri.edu. 


\section{CHICAGO JOURNALS}

Preindustrial and Postwar Economic Development: Is There a Link?

Author(s): John P. Burkett, Catherine Humblet, and Louis Putterman

Source: Economic Development and Cultural Change, Vol. 47, No. 3 (April 1999), pp. 471-495

Published by: The University of Chicago Press

Stable URL: http://www.jstor.org/stable/10.1086/452416

Accessed: 19/03/2013 11:26

Your use of the JSTOR archive indicates your acceptance of the Terms \& Conditions of Use, available at

http://www.jstor.org/page/info/about/policies/terms.jsp

JSTOR is a not-for-profit service that helps scholars, researchers, and students discover, use, and build upon a wide range of content in a trusted digital archive. We use information technology and tools to increase productivity and facilitate new forms of scholarship. For more information about JSTOR, please contact support@ jstor.org. 


\section{Preindustrial and Postwar Economic Development: Is There a Link?*}

John P. Burkett

University of Rhode Island

Catherine Humblet

Federal Reserve Bank of Boston

Louis Putterman

Brown University

Everybody knows now that the "hardware" dimension of development - the physical infrastructure, for example - is a lot easier to put in place than the "software" to keep it operable, which depends on local skills and institutions. (United Nations Development Programme) ${ }^{1}$

\section{Introduction}

Since the end of the Second World War, former colonies and other less developed countries in Africa, Asia, and Latin America have been viewed as taking part in a race toward modern economic development, with widely varying results. During the past decade, the question of why some countries' economies have grown rapidly and others slowly or not at all has helped to motivate a new body of research using a variety of neoclassical growth models and cross-country regression techniques. Such studies have generally supported the hypothesis that growth rates are a positive function of investment rates and that they are a negative function of initial income- that is, that poorer countries tend to grow faster, all else being equal. In some cases, they have also supported additional hypotheses, such as those linking growth to education, to government policies, or to other variables, including political stability or ethnic heterogeneity. However, an important part of the variation in growth rates typically remains unexplained, and this unexplained variation is 
strongly correlated with the regions in which countries are situated, a seemingly noneconomic variable.

In this article, we provide evidence for the hypothesis that a substantial portion of the conventionally unexplained variation in performance among LDCs is due to differences in economic and social preconditions to modern economic growth that have not heretofore received systematic attention in the economics literature. The new growth literature treats all countries as being on a par in the growth race, but for the types of variables mentioned above. The old postwar literature on economic development itself typically recognizes two basic states or stages of development: the traditional, preindustrial, or underdeveloped and the modern, industrial, or developed. ${ }^{2}$ The departure of this study is to provide evidence that conceptualizing long-run social and economic development-most of it preceding the modern era-as a multistage process sheds light on the differential performances of countries in recent decades. ${ }^{3}$ In particular, we turn our attention to the initial position of societies composing a present-day nation on a production-system-intensity continuum that stretches from low-population-density hunter-gatherer societies, on the one extreme, to high-population-density agriculturebased societies marked by large states, taxation, and specialized commerce, on the other. We propose that this position is an important predictor of a nation's growth performance in recent decades, even after controlling for the determinants of growth treated in the standard literature. ${ }^{4}$ This link between preindustrial economies and recent growth performance suggests that premodern economies left their traces on societies' stocks of human and perhaps physical capital in ways that are not adequately measured by flows or stocks of formal schooling, initial income, or investment. Our hypothesis is that societies that are located closer to the high-intensity end of the continuum of premodern economic formations require a less dramatic transformation, in terms of economic practices and behaviors, and thus tend to make the shift to industrialization more rapidly than those societies that are located nearer to the opposite end of this continuum. ${ }^{5}$

\section{Premodern Economies and Modern Development Capacity}

With its focus on modern market economies, or in some instances on the transition to industrialization, neoclassical economics has generally been content to view economies as fundamentally similar, or to distinguish, at most, between "traditional" and "modern" ones. However, in the longer view of human development taken by many anthropologists, archeologists, and demographers, human society has passed through numerous stages between the primitive era of hunting and gathering and the industrial societies of today's more developed countries. The thesis of this article is that the type of economy that characterized today's nation-states before they began their transition to industrialization is likely 
to have an impact on the speed with which they make that transition. Economies starting from "less developed" positions in terms of the developmental hierarchy of E. Boserup and others will initially experience slower growth, as it takes longer for them to achieve the preconditions of modern development that must be embodied in the broad human and perhaps also physical capital of their societies. Under "broad human capital" we include attitudes and capabilities that may fall outside the scope of formal education, as well as a stock of ideas and knowledge that is held collectively by a population through a complex division of cognitive labor, and that may not be sufficient if imparted only to a few individuals. ${ }^{6}$ Forms of premodern physical capital may include canal and irrigation systems, which may have low or nonexistent market valuations and which will be little reflected in a country's income at the onset of industrialization because their effects on output tend to be roughly offset by corresponding effects on population.

Why should we expect that the characteristics of premodern societies have helped to determine the growth performances of modern nations in recent decades, when all faced similar conditions of national independence, of exposure to world trade and technology, and of at least bi- and multilateral support for development? Six possibilities that we merely list, for brevity, are (a) that the premodern legacy influences conceptions and practices of productive activity, including willingness to supply arduous hours of work, which is hypothesized to be greater among intensive agriculturalists than among extensive farmers or pastoralists; $(b)$ that premodern technical skills differ in their similarity to those needed in industrial societies, with those of advanced agrarian societies being more readily adapted to industrial needs; $(c)$ that there is greater economic independence of households and a higher degree of commercialization and trade in advanced agricultural societies; $(d)$ that agricultural societies had a head start for modern state development conferred by premodern experience with large-scale polities; $(e)$ that there are related advantages conferred by greater social homogeneity, which is established across larger groups where state-level organization was achieved earlier; and $(f)$ that higher population density lowers the cost of internal trade.

\section{Testing the Hypothesis}

There are a variety of ways in which one can investigate linkages between contemporary nations' recent economic performance and the types of premodern economies that they had. In this article, we test the hypothesis on cross-country data, as in the recent growth literature mentioned in our introduction. Our approach is to adopt a growth equation that matches closely those used in other studies and to add to it independent variables as a proxy for the preindustrial development (PID) stage of each included country. While we have no argument with the view that this methodology has reached a point of diminishing returns in many ap- 
plications, the long-view approach pursued here is unlike any in the extant growth literature, and we adopt the standard cross-country format to control for other variables as well as to facilitate comparability with other studies. ${ }^{7}$ A key question remains how PID is to be measured.

While some conceptually interesting approaches can be thought of, most run up against problems of data availability. However, there exist data for a reasonably large number of countries on three relevant indicators of social evolutionary development. First, information on population density before the recent push for development should be indicative of developmental stage, according to the Boserupian framework. Second, widely available information on the amount of land cultivated per farmer can be treated as a proxy for cultivation intensity, another indicator of the proposed evolutionary continuum. Third, information on the proportion of the cultivated land that is irrigated may also indicate productionsystem intensity. Irrigation systems directly require additional labor for construction and management, and for agricultural tasks such as sowing multiple crops on a given parcel. Irrigation systems are therefore historically associated with higher population densities, as well as with statelevel organization, taxes, written language, and social stratification.

The three indicators are not necessarily without drawbacks. It might be more instructive to look at the population density of each country's inhabited areas, so that density figures used are not influenced by arbitrary variation in the amount of uninhabitable wasteland within its borders. However, population per unit of cultivated land, an available rough proxy for population density of each country's inhabited area, is highly correlated with farmers per hectare. Since we get more information by focusing on the two distinct variables, we retain them and briefly report tests with the alternative variable in Section $\mathrm{V} .{ }^{8}$

Problems with the farmer-to-land ratio include its lack of controls for the prevalence of noncultivating modes like hunting-and-gathering or pastoralism. ${ }^{9}$ Recourse to irrigation is arguably an outcome of unfavorably timed rainfall. ${ }^{10}$ Failure to control for soil quality may also be a problem. However, the ideal way to do that is unclear, and indeed Boserup and others have argued that soil quality is to a significant degree an endogenous outcome of cultivation intensity (including mixed husbandry and agriculture practices).

Perhaps the most serious problem with the measures that are available is the lack of broad cross-country data for periods earlier than World War II. We are forced, therefore, to treat the data on population densities, cultivation intensities, and irrigation rates in the early 1960s as proxies for the preindustrial economic orders of today's developing countries. In one case we were able to test the adequacy of these proxies. Population density data for 1911 are available for a total of 76 countries, of which 66 also provide data for 1960 . It is reassuring that the simple correlation 
between the two sets of measures is .8199, and the Pearsson rank correlation is .8960 , which has a $p$-value of .0001 . Tests of our hypothesis using the 1911 values for the subsample providing them are reported below. However, the main part of our analysis is done with 1960 values, which are available for a much larger sample of countries and for all three of our PID measures.

The rest of our growth equation follows the format suggested by R. Levine and D. Renelt, who surveyed a number of cross-country growth studies. ${ }^{11}$ Like Levine and Renelt, we regress the rate of growth of GDP per capita for a cross-section of countries on four principal independent variables - initial GDP per capita, average investment share in GDP, population growth rate, and measures of formal education. Including initial GDP per capita controls for the possibility that poorer countries will grow faster as a result of forces toward convergence of development levels. Investment and education are expected to be positively associated with growth, while high population growth might slow economic growth due to higher per capita costs for education and social services, among other factors. ${ }^{12} \mathrm{We}$ add one more variable, aside from our PID measures, to the basic Levine and Renelt data set. Measures of price distortion used in several recent growth studies are excellent predictors of growth performance. ${ }^{13}$ There are good economic grounds for expecting this to be the case, since distorted prices can lead to misallocation of resources and thus to lower returns on given levels of investment and of resource endowments. We use the black market premium measure, which seems most satisfactory from a conceptual standpoint. ${ }^{14} \mathrm{Fi}$ nally, as in the articles cited, we check for the explanatory adequacy of the included economic variables by including dummy variables in some estimates for the sub-Saharan African and Latin American regions.

Our data on population density, cultivation intensity, and irrigation are drawn mainly from the F.A.O. Production Yearbooks. ${ }^{15}$ The data on the conventional growth equation variables, including the black market premium, are drawn from the data set assembled by R. Barro and J.-W. Lee. Growth rates of real GDP, GDP per capita, and the investment ratio in the latter data set are from R. Summers and A. Heston. ${ }^{16}$

Before presenting our results, it is worth emphasizing that our prediction regarding the effects of population density and the farmer-to-land ratio is exactly the reverse of what was the conventional wisdom in the field of development economics around 1960. At that time, "overpopulation" and paucity of natural resources relative to mouths to feed were thought to constitute severe handicaps for development in most of Asia, while the much more "favorable", balance between population and resources led to much optimism about Africa's prospects, with Latin America's outlook judged to lie somewhere in between. Our hypothesis is that what had been taken as an opportune balance between resources 
and population was really an indication of a less favorable position on the PID continuum and, thus, a hint of the possibility that the road to modern economic growth might be a longer, rather than a shorter, one.

\section{Estimation and Results}

To assess the influence of PID variables on growth we apply regression analysis to data on a cross-section of nations. Our most general specification of the regression model is as follows:

$$
\begin{aligned}
y_{i} & =\alpha^{\prime} x_{i}+\epsilon_{i} \\
\operatorname{Var}\left(\epsilon_{i}\right) & =\exp \left(\beta_{0}+\beta_{1} q_{i}\right) \\
i & =1, \ldots, n,
\end{aligned}
$$

where $y_{i}$ is the average annual growth rate (in decimal form) of per capita GDP for country $i$ for $1960-90, \alpha$ is a $12 \times 1$ vector of unknown coefficients, and $x_{i}$ is a $12 \times 1$ vector of regressors for country $i$, whose first element is 1 and whose other elements are the following:

2. GDP60: GDP per capita in 1960;

3. Inv6090: Investment divided by GDP, averaged over 1960-90;

4. GPop6090: Growth rate of population (in decimal form), 1960-90;

5. Sec60: Share of children of secondary school age attending secondary schools (in decimal form) in 1960;

6. BMP6090: Black market premium, averaged over 1960-90;

7. Popden60: Population per hectare of land surface in 1960;

8. Manland60: Agricultural population per cultivated hectare in 1960;

9. Irrig60: Fraction of cultivated land that was irrigated in 1960;

10. PC1: First principal component of the previous three variables;

11. SAfrica: Dummy variable for sub-Saharan Africa;

12. LaAm: Dummy variable for Latin America.

The term $\epsilon_{i}$ is a stochastic disturbance-including a measurement error for the dependent variable-whose distribution may exhibit heteroskedasticity of the form indicated by equation (2); $\beta_{0}$ and $\beta_{1}$ are unknown parameters; and $q_{i}$ is a quality rating for the GDP data of country $i$. This quality rating ranges from 1 for countries with the lowest quality data (a rating of $\mathrm{D}-$ ) to 11 for those with the highest quality data (a rating of A). ${ }^{17}$ We report weighted least squares estimates of $\alpha$ whenever an ordinary least squares (OLS) estimate of $\beta_{1}$ is negative and otherwise report OLS estimates of $\alpha .^{18}$

Conventional economic theory and previous empirical work suggest that the coefficients of GDP60, GPop6090, and BMP6090 should be negative and those of Inv6090 and Sec60 should be positive. We expect any one of our four proxies for PID (Popden60, Manland60, Irrig60, and 
TABLE 1

Averages for Different Subgroups of Countries

\begin{tabular}{lccc}
\hline Variable Name & $\begin{array}{c}\text { Sub-Saharan } \\
\text { Africa } \\
(32)\end{array}$ & $\begin{array}{c}\text { South, Southeast, } \\
\text { and East Asia } \\
(13)\end{array}$ & $\begin{array}{c}\text { Latin } \\
\text { America } \\
(22)\end{array}$ \\
\hline GDP per capita, 1960 & 842.533 & 1040.615 & 2185.091 \\
Growth rate of GDP per capita, & {$[30]$} & {$[13]$} & {$[22]$} \\
1960-90 & $.7 \%$ & $3.8 \%$ & $1.2 \%$ \\
Population density, 1960 & {$[21]$} & {$[10]$} & {$[19]$} \\
Farmers per hectare, 1960 & .314 & 5.607 & .394 \\
& {$[32]$} & {$[13]$} & {$[22]$} \\
Irrigated share of cultivated land, & {$[29]$} & 5.447 & 1.55 \\
1960 & 2.8 & {$[12]$} & {$[22]$} \\
& {$[22]$} & 22.992 & 9.445 \\
\end{tabular}

NoTE.-Numbers in parentheses represent the number of countries in each subgroup. Numbers in square brackets represent the sample size for each average measure.

PC1) to have a positive estimated coefficient if the other proxies are omitted. Thus, the same should be the case for their first principal component. ${ }^{19}$ Previous empirical work suggests that the estimated coefficients of the regional dummies are likely to be negative.

Before turning to our statistical results, consider table 1, which shows the means of GDP per capita in 1960, of the growth rate of real GDP per capita from 1960 to 1990, and of our three measures of PID, for the sample countries located in sub-Saharan Africa (SSA), in Asia excluding the Middle East, and in Latin America. Together they account for $85 \%$ of the sample of countries included in the exercises of tables 24. ${ }^{20}$ Table 1 provides some intuition for the results presented below, as it shows that the Asian countries exhibit the highest average population density, number of farmers per acre cultivated and irrigated share of cultivated area, and the highest rates of growth during 1960-90; that the sub-Saharan African countries exhibit the lowest average levels of all of these variables except farmers per hectare; and that the Latin American countries occupy the middle positions except with regard to the latter variable, farmers per hectare, with an average that is slightly smaller than SSA's. Growth rates are not obviously correlated with initial GDP per capita across these groups.

The number of countries that provide sufficient data for inclusion in our estimates varies depending on which if any proxies for PID are used. For ease of comparison, in table 2 we report estimates of the vector $\alpha$ for the common sample for which all three PID measures, as well as the standard growth regression variables, are available, but in our discus- 
sion we also refer to the results obtained for the sample of maximum size for the specification of a given column. In our main analysis, we include all countries that did not belong to the Organization for Economic Cooperation and Development (OECD) in 1990 and for which sufficient data were provided in our sources. This yields a sample of 48 countries when no PID variables are used, 46 countries when only population density is used, 44 countries when only land per farmer is used, 42 countries when only irrigation intensity is used, and 41 countries when all three PID variables, or their first principal component, are used. (See table A1 for a list of included countries.) Constraining the last six elements of $\alpha$ to equal zero, we obtain the estimates shown in the first column. These have the expected signs, and for three of the five explanatory variables they are significant at the .05 level or better. This column indicates that our sample of countries is similar to samples analyzed in previous studies with regard to the relationship between the dependent variable and the conventional regressors. ${ }^{21}$

In columns 2-5 we add the three basic PID variables and their first principal component to the regression, one at a time. The estimated coefficients are in each case positive and significant at the .01 level. In column 6 we report the results of including the regional dummy variables in the regression. Their estimated coefficients are negative and significant, as they have been in several previous studies. Finally, in column 7 are the results of including $\mathrm{PC} 1$ as well as the two regional dummies. Their estimated coefficients have the expected signs and are significant at the .01 level or better.

The hypothesis of this article is that PID has affected rates of economic growth in the postwar era. We do not assert that preindustrial growth affected industrialization similarly in all periods before 1945 or that it will do so indefinitely. Since we do not assert that the relationship between PID and growth will be stable over the very long run, it is relevant to test for its stability over time. To this end, we split the 1960-90 period into two, 1960-75 and 1975-90. Table 3 presents the results for the former subperiod, for which the dependent variable is the average annual growth rate of per capita GDP for 1960-75 and the periodspecific regressors are, in an obvious notation, Inv6075, GPop6075, and BMP6075. Table 4 presents the results for the latter subperiod, for which the dependent variable is the average annual growth rate of per capita GDP for 1975-90 and the period-specific regressors are, analogously, Inv7590, GPop7590, and BMP7590. We retain PID measures based on 1960 data, since these proxy PID at earlier dates and are not meant to track "initial PID' for the specific subperiod. ${ }^{22}$

For both subperiods, all estimated coefficients have the same signs as for the full period. In many cases the adjusted $R^{2}$ statistics and absolute values of $t$-statistics are a bit lower for both subperiods than for the full period, perhaps due to the greater influence of cyclical and random 


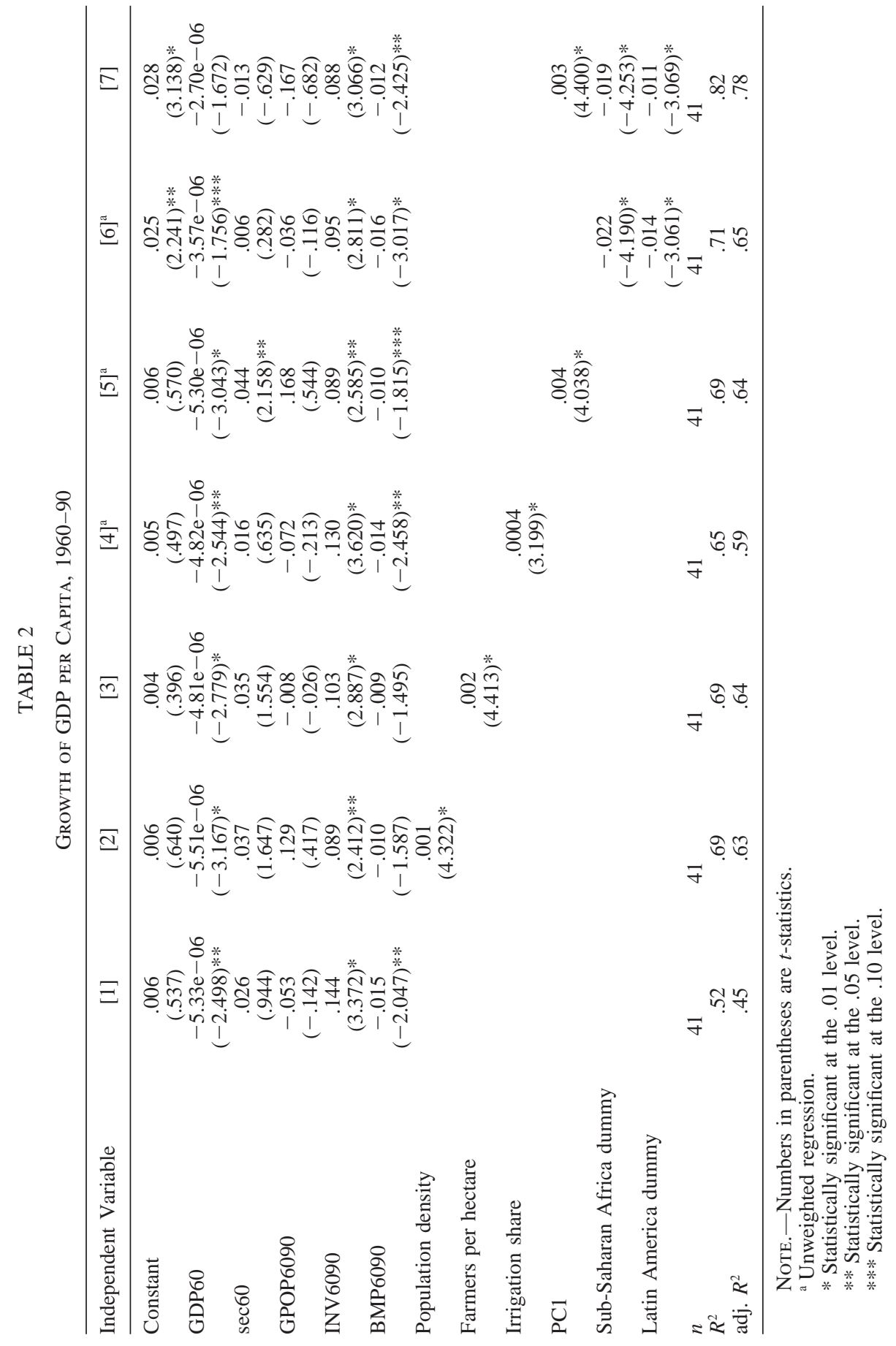




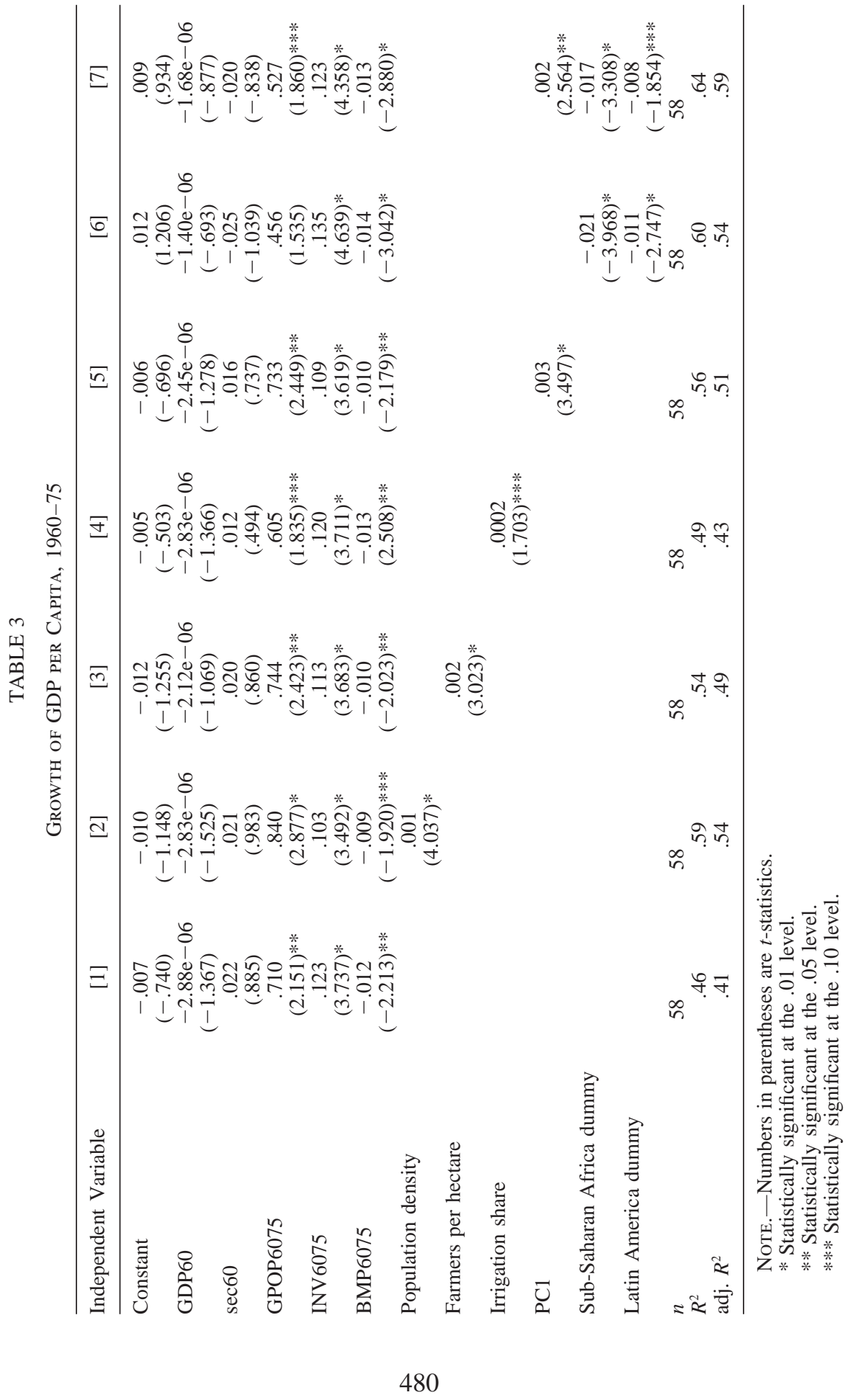




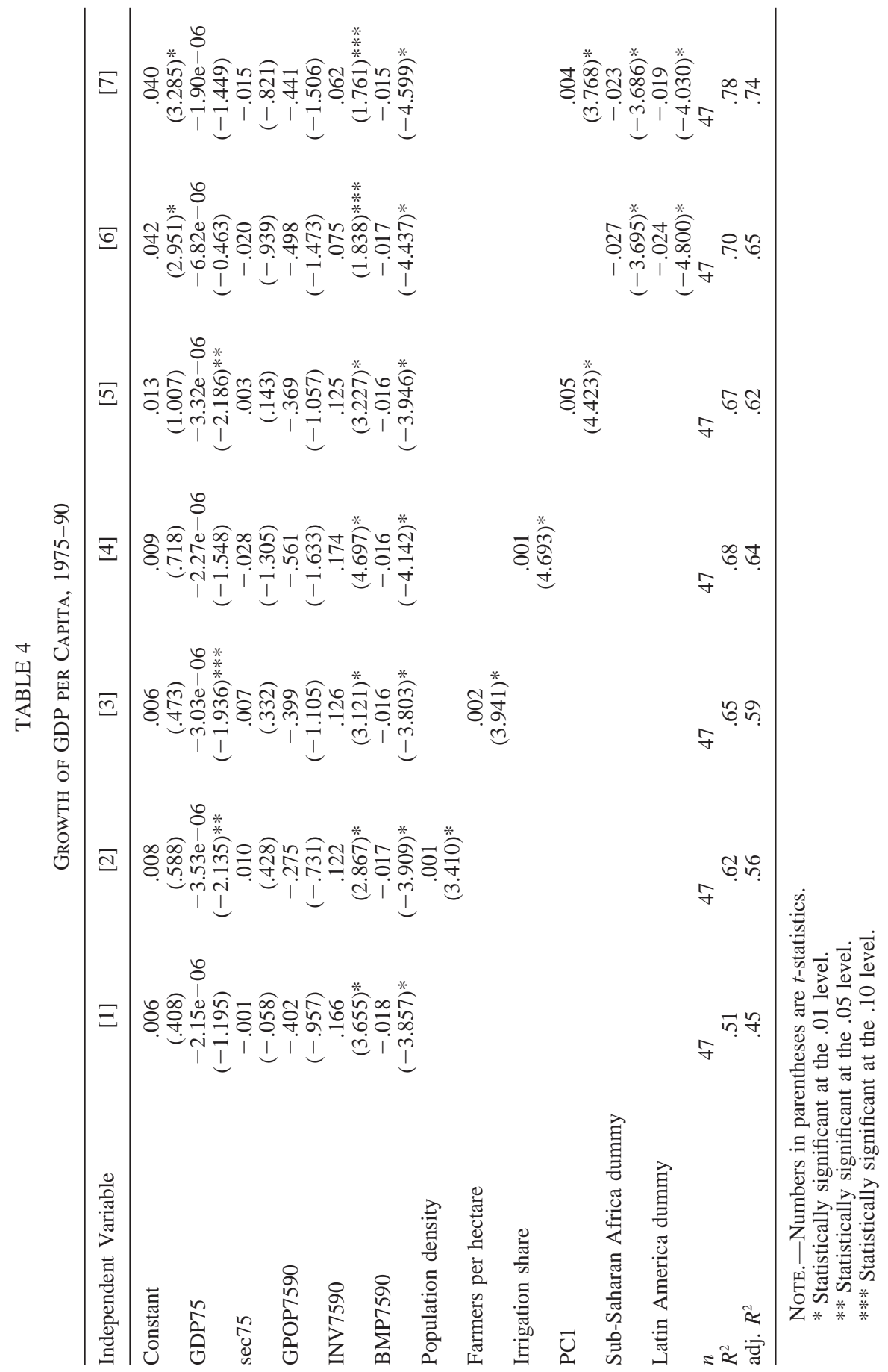

481 
influences on growth rates over shorter periods. Nonetheless, when the PID variables enter the regressions, their estimated coefficients are always positive at the .05 level, with the exception of the coefficient of irrigation share in the estimation for $1960-75$, which is significant at .10 level.

Based on the common sample results shown in tables $2-4$, both the familiar criterion of the adjusted $R^{2}$ statistic and the theoretically better justified Schwarz criterion always favor the model that includes PC1 and the regional dummies - that is, the model whose estimates are reported in the last column of each table. It may also be of interest to compare proportions of the total variance that are explained by the different models by reference to the $R^{2}$ statistics. In the results for the minimal common sample of 41 countries for 1960-90, we find that the $R^{2}$ statistics for models $1-7$ (1960-90) are .52, .69, .69, .65, .69, .74, and .82. Thus we can say that when a PID variable is added to model 1 , the increment to $R^{2}$ is at least .13 and typically .17 , an addition to explained variance similar to the .19 increment when only regional dummies are added. Comparing the results for columns 1 and 7 , we can say that the full model explains almost $30 \%$ more of the variance in growth rates than does the unaugmented model. The relative contribution of the PID variables to this extra explanatory power is comparable to that of the regional dummies. Either of the first two PID variables or PC1 alone explain $35 \%$ of the variance unexplained by the base model, the regional dummies (alone) explain $40 \%$ of that variance, and the addition of both explains the better part, or $62.5 \%$, of the otherwise unexplained variance. $^{23}$

Considering the units in which our variables are expressed, we can see that models 2, 3, and 4, estimated for 1960-90, imply respectively that a country's growth rate would have been increased one percentage point if in 1960 its population density had been 10 persons per hectare larger, if it had had five more farmers per cultivated hectare, or if its irrigation share had been 25 percentage points higher. An alternative way of expressing the economic importance of the PID variables is to compute "'beta-coefficients,', which indicate by how many standard deviations the dependent variable increases when an independent variable rises by one standard deviation. The beta coefficients for the PID variables, based on estimates for 1960-90, are .46 in model 2, .45 in model $3, .38$ in model $4, .42$ in model 5 , and .38 in model 7. Among the standard variables, only the investment ratio and the black market premium appear to have comparable impacts. ${ }^{24}$ Thus, the PID effects appear to have been substantial. Having had the "right history", was as important as having "gotten prices right." Although history, unlike prices, cannot itself be changed, nonetheless there may be policy implications of this finding, as we argue in the final section.

As mentioned earlier, we were unable to obtain data on most of the 
PID variables for years earlier than 1960, but we were able to find data on population density in 1911 for a subset of countries in our sample. To check the sensitivity of our results to demographic changes between 1911 and 1960, which could conceivably reflect contaminating influences of early industrialization efforts, we reestimated equations of the types shown in tables 2-4, using population density in 1911 rather than 1960. Since we do not have data on the other PID variables for a comparable date, we entered Popden 11 as the only PID variable in these runs. Table 5 shows the results of reestimating the equations corresponding to columns 1,2 , and a modified version of column 7 of table 2, for the 31 country subsample available for the 1960-90 period. The other results are roughly the same as those shown in table 2, and we find that the 1911 and 1960 values of population density perform almost identically when the same subsample of countries is examined, although the absolute value of the coefficient on Popden 11 is as much as an order of magnitude larger than that on Popden60. Not shown in table 5 are qualitatively identical results obtained for the 50-country sample for which parallel estimates can be performed for 1960-75, and for the 32-country sample for which this can be done for 1975-90. These exercises suggest that the PID variables, measured in 1960, which are used in the runs reported in the tables, are indeed good proxies for PID at a considerably earlier period. At least they do not lead to exaggerated estimates of the importance of preindustrial conditions to modern growth. Indeed, judging from these estimates, the estimates of tables 2-4, which use 1960 measures for PID, could significantly understate the magnitudes of the economic impact of PID, more accurately measured.

\section{Further Tests and Extensions}

While impressive, the tests reported above are by no means conclusive. Among other things, we would like to know how sensitive the results are to equation specification (e.g., the possibility of missing variables), sample, and the precise period analyzed. We have been able to conduct a few further explorations, which we report here, with further work remaining for the future.

First, we conducted some checks of the robustness of our conclusions to the composition of the developing-country sample. That sample includes all non-OECD countries with data for the variables under study, and it appears to be broadly representative of Africa, Asia, and Latin America. ${ }^{25}$ Checking the values of the PID variables, we found two countries, Hong Kong and Singapore, to have been substantial outliers, especially for population density and cultivation intensity. ${ }^{26}$ Hong Kong and Pakistan are also found to be outliers when irrigation share is the only PID variable. Reestimating the models without Hong Kong and Singapore, we find that the coefficients of the PID variables retain their expected positive signs and are usually little changed in magnitude, al- 


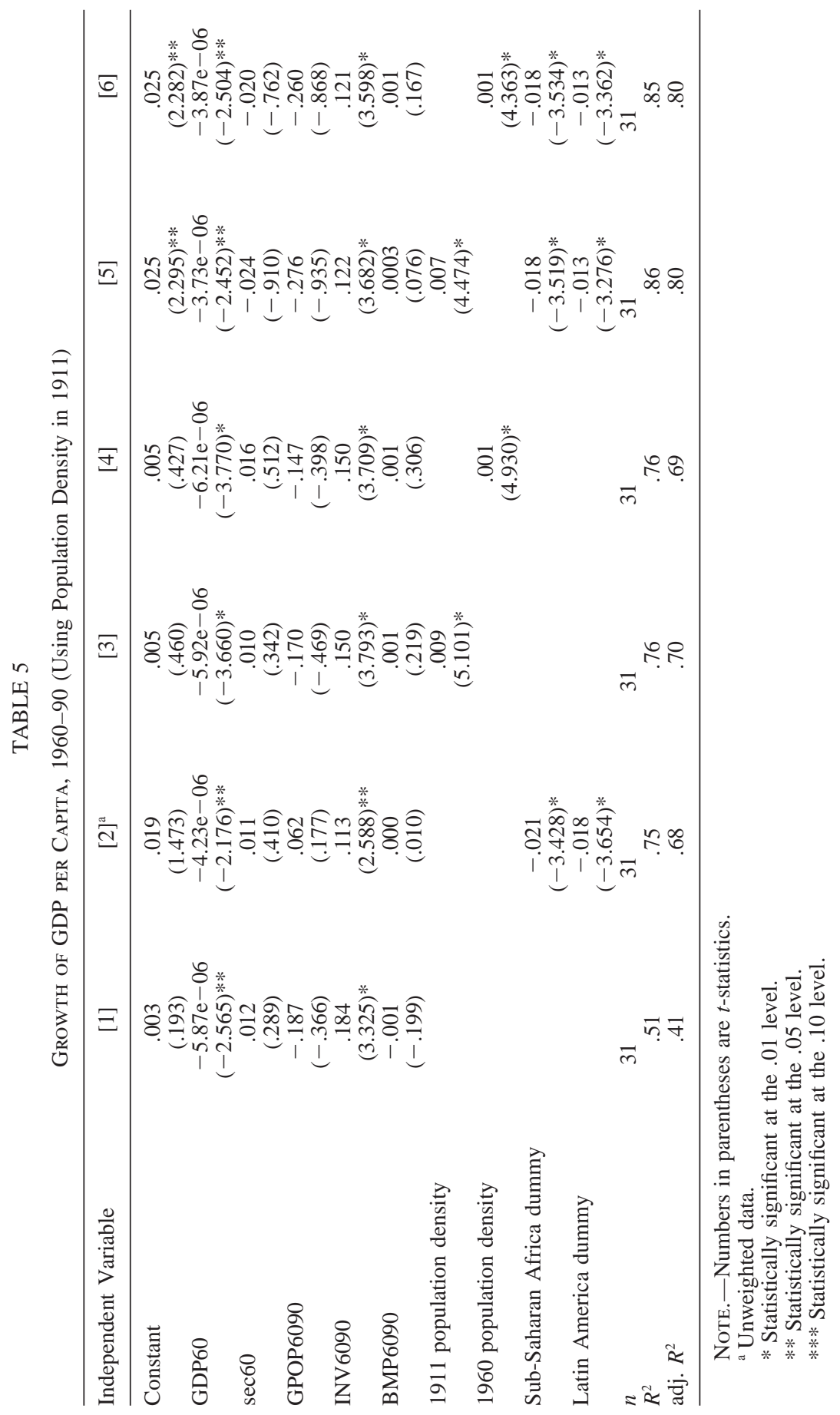


though their significance levels are often lower. However, when we allow better representation of the East Asian countries by adding observations for mainland China and South Korea (for which some data were lacking in the sources on which we relied for the rest of the sample), significance of the PID variables is no longer sensitive to inclusion of those outliers, as shown in table $6 .{ }^{27}$ Neither the coefficient estimates nor their significance levels are significantly affected by dropping any other country from the 41-country sample of the table 2 estimates.

Second, in view of the reservation raised above about the effects of wastelands on our population density variable, we estimated an equation paralleling models $2-4$ of tables $2-4$ but included the ratio of population to cultivated area in hectares as the lone PID measure. As expected, the coefficients on this variable are positive and significant at levels (always better than .01) similar to those on Popden60 and Manland60 for the full period and both subperiods. The coefficient on the new variable is also positive and significant at the .05 level or better when China and South Korea are added to the sample or are substituted for outliers Hong Kong and Singapore. ${ }^{28}$

The possibilities for investigating the impact of excluding relevant variables are virtually endless. We confined our initial investigations to three sets of variables. First, we were impressed with the impact of ethnic heterogeneity in explaining, in particular, Africa's relative performance, as shown by W. Easterly and R. Levine. ${ }^{29}$ To investigate the degree to which their ethnic heterogeneity variables might capture the same influences reflected by our PID measures,${ }^{30}$ we reestimated models 5 and 7 for the three periods of tables $2-4$ adding in turn the two main measures of ethnic heterogeneity used by Easterly and Levine. ${ }^{31}$ In the resulting estimates, the coefficient on PC1 remains significant at the .01 level (usually with slightly increased significance) with almost no change in its point estimate. Ethnic heterogeneity has the expected sign but is significant at the .05 level only for the $1960-90$ period, when PC1 is included. ${ }^{32}$

Second, the possibility was raised that the PID variables might be serving as imperfect proxies for "initial health capital" and that the estimates of their effects might be biased by exclusion of more direct measures of that variable from our equations. We accordingly carried out a set of estimates in which life expectancy at birth in 1960 was added to the explanatory variable set of model $7 .{ }^{33}$ The results showed that the coefficient on life expectancy is indeed positive and significant in this setting, but that the addition of this variable does not change the sign or significance level of PC1 or of the individual PID variables in their respective equations. ${ }^{34}$

Third, we were intrigued by J. Sachs and A. Warner's apparent success in explaining differences between African and non-African economic growth using a number of different policy and resource vari- 


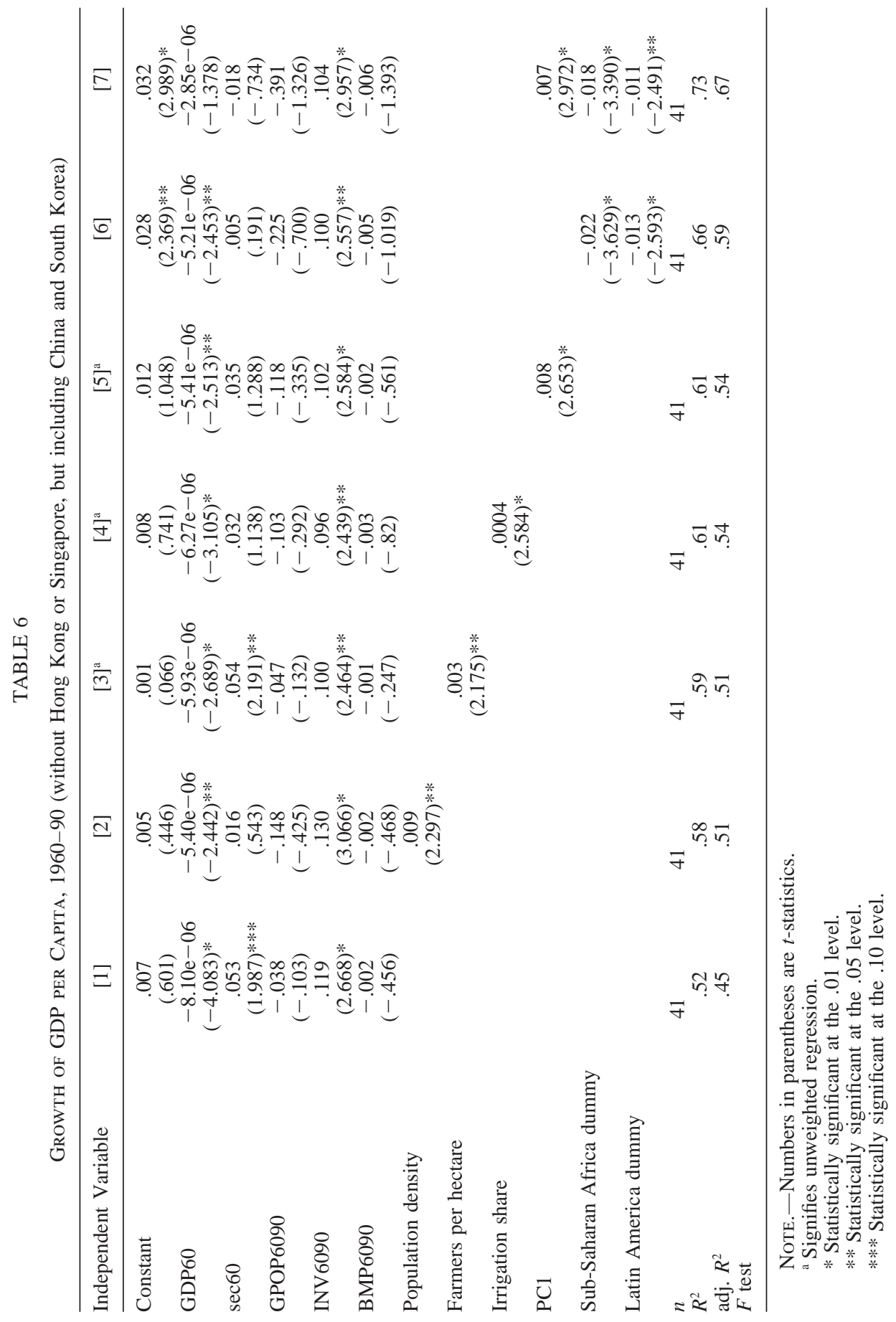

486 
ables. ${ }^{35}$ Unlike other studies, Sachs and Warner show that the dummy for sub-Saharan Africa (along with ethnic heterogeneity and the growth rates of neighboring countries) becomes insignificant when variables including life expectancy, the natural resource export fraction of GDP, central government saving, tropical climate, access to the sea, and indicators of openness to trade are controlled for. Sachs and Warner's specification differs from the regressions so far reported in a variety of ways. To keep our investigation manageable, we tested whether the effects of PID remain significant even after controlling for the variables used by Sachs and Warner both by $(a)$ adding their distinctive variable set to the set of explanatory variables in our model 7 , and $(b)$ by adding our PID variables to the explanatory variables in their most comprehensive model, shown in table 2 of their paper. It is not possible to report the full set of results here, but it can be summarized by stating that in some settings at least the PID variables appear to explain some of the growth variance left unexplained by the variables that Sachs and Warner used, just as it explains otherwise unexplained variance in the models shown in tables $2-6 .^{36}$

Finally, while our hypothesis is meant to apply mainly to countries at an early stage of industrialization during the postwar period, it is interesting to investigate whether it holds at some broad level when all countries for which the relevant data are available, including those of Western Europe and other OECD member states, are included. During the postwar era, the growth performances as well as the population densities, cultivation intensities, and irrigation ratios of European countries were on average intermediate between those of Asia and of Latin America. ${ }^{37}$ We reestimated the equations of tables 2-4, adding European and other OECD countries, and found that our hypothesis appears to hold as well or better for this larger sample. As might be expected, the improvement is less noticeable when all of the OECD countries are added, because the United States, Canada, Australia, and New Zealand have European-like economies but lower population densities and more land per farmer. ${ }^{38} \mathrm{By}$ contrast, inclusion of Japan, a high-density and high-growth country, strengthens the qualitative result of the tables with respect to the PID variables. These results suggest that the linkage between PID and modern economic growth that is hypothesized in this article has been a worldwide phenomenon and not one that holds only for the less developed countries. ${ }^{39}$

\section{Implications and Conclusion}

We have shown that any one of our three indicators of PID typically contributes as much to the explanation of recent economic growth as do any of the more standard variables analyzed by Barro, Levine and Renelt, and others, and that the addition of these variables to their equations explains roughly the same fraction of the growth residual otherwise picked 
up by regional dummies and the better part (57\%) of that majority of the growth residual that is explained when both PID indicators and regional dummies are added. If the trends highlighted by this initial exploration were to be confirmed, what would be their implication for economic policy? Since the PID variables are givens to each country from the present standpoint, what does their inclusion in our study contribute beyond what we already know from the significance of regional dummy variables or of such exogenous factors as the tropical climate dummy used by Sachs and Warner?

While our analysis suggests only that three demographic and resource variables have influenced recent economic growth, we propose that these variables are indicators of stages along a long-term historical development continuum. We argue that the reason why a country's PID status helps to determine its measured performance in the early decades of the push for modern economic growth is that different countries' human-capital stocks broadly understood as including informal learning, culture, and the collective knowledge base, as well perhaps as certain physical infrastructures like canals and irrigation networks, were differentially pre-positioned to respond to the possibility of modern growth. ${ }^{40}$

To tease out further implications from the analysis, we need to ask how the paths traveled by each country both in the recent past and in the near future are likely to affect the preparedness for industrialization. For us, the idea that ways of economic life in their entirety influence countries' capacities for modern economic development suggests that the way forward for the less-developed countries should include attention not only to the impact of formal education, ${ }^{41}$ but also to that of a wider array of factors including citizens' participation in market activity, employment, exposure to modern ideas and practices, and opportunities for entrepreneurship. Since favorable changes with respect to these factors could influence positively the long-term capacity for development in ways that may not show up for some time in output figures, improvement in the human base for development might be treated as a medium-term goal in its own right. Put differently, our results may be seen as providing support for the "capacity-building"' emphasis in some recent development programs. But exactly what form effective human-development efforts should take is beyond the scope of our discussion. 


\section{Appendix}

TABLE A1

Country List

\begin{tabular}{|c|c|c|c|c|c|c|}
\hline & \multicolumn{2}{|c|}{ 1960-90 } & \multicolumn{2}{|c|}{$1960-75$} & \multicolumn{2}{|c|}{$1975-90$} \\
\hline & [2] & [6] & [2] & [6] & [2] & [6] \\
\hline \multicolumn{7}{|l|}{ Sub-Saharan Africa: } \\
\hline \multicolumn{7}{|l|}{ Angola } \\
\hline \multicolumn{7}{|l|}{ Benin } \\
\hline \multicolumn{7}{|l|}{ Botswana } \\
\hline \multicolumn{7}{|l|}{ Burundi } \\
\hline \multicolumn{7}{|l|}{ Cameroon } \\
\hline \multirow{2}{*}{\multicolumn{7}{|c|}{$\begin{array}{l}\text { Central African Republic } \\
\text { Chad }\end{array}$}} \\
\hline & & & & & $\sqrt{ }$ & \\
\hline Congo & $\checkmark$ & & $\checkmark$ & & $\checkmark$ & \\
\hline \multicolumn{7}{|l|}{ Gabon } \\
\hline \multicolumn{7}{|l|}{ Gambia } \\
\hline \multicolumn{7}{|l|}{ Ghana } \\
\hline \multicolumn{7}{|l|}{ Kenya } \\
\hline \multirow{2}{*}{\multicolumn{7}{|c|}{ Lesotho }} \\
\hline & & & & & & \\
\hline \multicolumn{7}{|l|}{$\begin{array}{l}\text { Liberia } \\
\text { Madagascar }\end{array}$} \\
\hline \multicolumn{7}{|l|}{$\begin{array}{l}\text { Malawi } \\
\text { Mauritania }\end{array}$} \\
\hline \multirow{2}{*}{\multicolumn{7}{|c|}{$\begin{array}{l}\text { Mauritania } \\
\text { Mali }\end{array}$}} \\
\hline & & & & & & \\
\hline Mauritius & & & & & $\sqrt{ }$ & \\
\hline Mozambique & & & $\checkmark$ & $\checkmark$ & & \\
\hline Niger & & & $\sqrt{ }$ & $\checkmark$ & & \\
\hline Nigeria & $\checkmark$ & $\checkmark$ & $\checkmark$ & $\checkmark$ & $\checkmark$ & $\checkmark$ \\
\hline Rwanda & $\checkmark$ & & $\sqrt{ }$ & & $\checkmark$ & \\
\hline Senegal & $\sqrt{ }$ & $\checkmark$ & $\sqrt{ }$ & $\checkmark$ & $\sqrt{ }$ & $\checkmark$ \\
\hline Sierra Leone & & & & & $\sqrt{ }$ & $\checkmark$ \\
\hline South Africa & $\checkmark$ & $\checkmark$ & $\checkmark$ & $\checkmark$ & $\sqrt{ }$ & $\mathrm{J}$ \\
\hline Sudan & & & & & $\sqrt{ }$ & $\checkmark$ \\
\hline Tanzania & & & $\checkmark$ & $\checkmark$ & & \\
\hline Togo & $\checkmark$ & $\checkmark$ & J & J & $\sqrt{ }$ & $\checkmark$ \\
\hline Uganda & & & J & J & & \\
\hline Zaire & & & J & & & \\
\hline Zambia & $\checkmark$ & $\checkmark$ & j & $\checkmark$ & $J$ & $\checkmark$ \\
\hline Latin America: & & & & & & \\
\hline Argentina & $\checkmark$ & $\checkmark$ & $\checkmark$ & $\checkmark$ & $\checkmark$ & $\checkmark$ \\
\hline Bolivia & $\checkmark$ & $\sqrt{ }$ & $\sqrt{ }$ & $\sqrt{ }$ & $\sqrt{ }$ & $\checkmark$ \\
\hline Brazil & $\checkmark$ & $\checkmark$ & $\checkmark$ & $\checkmark$ & $\sqrt{ }$ & $\checkmark$ \\
\hline Chile & $\checkmark$ & J & $\checkmark$ & $\checkmark$ & $\sqrt{ }$ & $\checkmark$ \\
\hline Colombia & $\checkmark$ & $\checkmark$ & $\checkmark$ & $\checkmark$ & $\sqrt{ }$ & $\checkmark$ \\
\hline Costa Rica & $\checkmark$ & $\checkmark$ & $\checkmark$ & $\checkmark$ & $\sqrt{ }$ & J \\
\hline Dominican Republic & $\sqrt{ }$ & $\sqrt{ }$ & $\sqrt{ }$ & $\sqrt{ }$ & $\sqrt{ }$ & $\checkmark$ \\
\hline Ecuador & $\checkmark$ & $\checkmark$ & $\checkmark$ & $\sqrt{ }$ & $\sqrt{ }$ & $\checkmark$ \\
\hline El Salvador & $\checkmark$ & J & $\checkmark$ & $\checkmark$ & $\sqrt{ }$ & $\checkmark$ \\
\hline Guatemala & J & J & J & $\checkmark$ & $\sqrt{ }$ & $\checkmark$ \\
\hline Guyana & & & & & $\sqrt{ }$ & $\checkmark$ \\
\hline Haiti & & & l & $\checkmark$ & & \\
\hline Honduras & $\checkmark$ & $\sqrt{ }$ & $\sqrt{ }$ & $\sqrt{ }$ & $\sqrt{ }$ & $\checkmark$ \\
\hline Jamaica & & & $\checkmark$ & $\checkmark$ & & \\
\hline Mexico & $\checkmark$ & J & $\checkmark$ & $\checkmark$ & $\checkmark$ & $\checkmark$ \\
\hline Nicaragua & & & $\sqrt{ }$ & $\sqrt{ }$ & & \\
\hline
\end{tabular}


TABLE A1 (Continued)

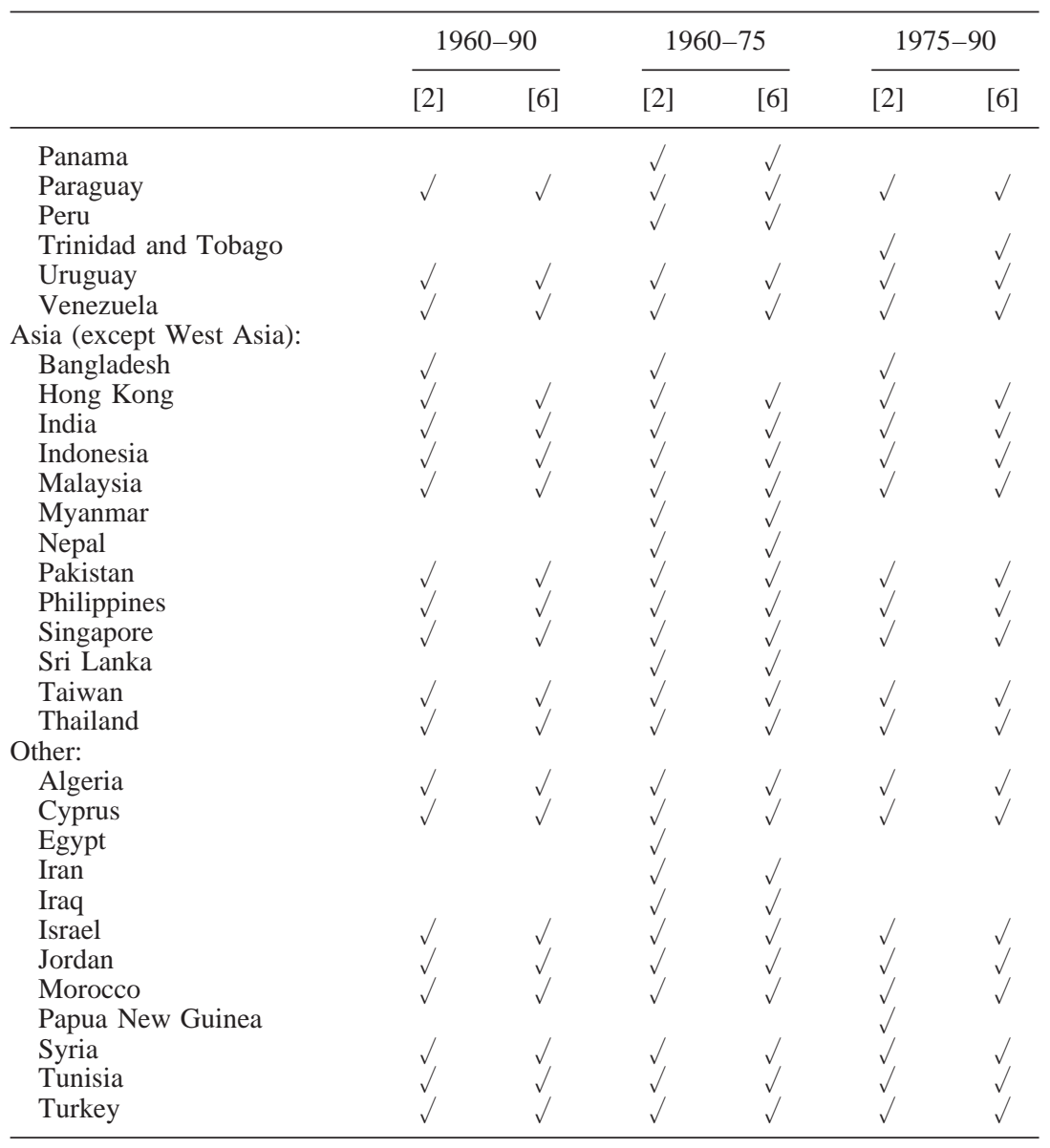

NoTE.-A check indicates that all data required for the specification of the indicated column corresponding to tables 2-4 are available. In the case of the column [2] specification, this means that the country observation is included in the maximum sample estimates reported in the text. All estimates shown in tables 2-4 are for the samples for which the column [6] and [8] specification can be estimated. Results for samples that include countries having a check under [2] but not [6] are mentioned in the text but not shown in tables $2-4$.

\section{Notes}

* We are grateful to Ambar Narayan, who completed the final phases of computational work for this article. We wish to thank Brown University's Undergraduate Teaching Research Assistantship Program, the Department of Economics, and the Watson Institute for International Studies at Brown University for support of research assistance. We thank David Weil for his valuable advice on growth models and data, Renu Sharma for research assistance on an early 
phase of this project, William Bassett for computational assistance, and Andrew Warner for help in accessing the Sachs and Warner data set used in a portion of our analysis. Finally, we thank the editor and an anonymous referee for providing valuable suggestions for improving the article. Correspondence may be sent to Putterman at Brown University or by e-mail: Louis_Putterman@brown.edu.

1. United Nations Development Programme, Regional Bureau for Africa, and Development Alternatives, Inc., Rethinking Technical Cooperation: Reforms for Capacity Building in Africa, Elliot Berg, coordinator (New York: UNDP, 1993), pp. 59-60.

2. Even W. W. Rostow's well-known Stages of Economic Growth (New York: Cambridge University Press, 1990) dealt only with steps in the transition from a basically undifferentiated "traditional" economy and thus bears no similarity to the multistage conceptions discussed below.

3. Ester Boserup, Conditions of Agricultural Growth: The Economics of Agricultural Change under Population Pressure (New York: Aldine, 1965), and Population and Technology (Oxford: Basil Blackwell, 1981); Elman Service, Cultural Evolutionism: Theory in Practice (New York: Holt, Rinehart \& Winston, 1971); Allen Johnson and Timothy Earl, The Evolution of Human Societies: From Foraging Groups to Agrarian State (Stanford, Calif.: Stanford University Press, 1987). Marvin Goodfriend and John McDermott, "Early Development," American Economic Review 85 (March 1995): 116-33, make a similar departure from past economic literature by modeling development as a series of stages, in their case a premarket period, a period of preindustrial market development, and modern industrial growth. Human capital and population density also play crucial roles in their approach, as they do in this article. However, theirs is largely a theoretical exercise, does not posit a continuum of developmental stages, and does not predict a link between stage of preindustrial growth and postwar economic performance.

4. Although hunter-gatherers were already of marginal significance on the eve of the worldwide spread of industry, a good part of that continuum continued to be represented.

5. An earlier exposition of these ideas is found in Louis Putterman, "Social Capital and Development Capacity: The Example of Rural Tanzania," Development Policy Review 13 (March 1995): 5-22. A somewhat expanded treatment of the ideas summarized in the present article is given in John Burkett, Catherine Humblet, and Louis Putterman, "Pre-Industrial and Post-War Economic Development: Is There a Link?' Working Paper no. 96-25 (Brown University, Department of Economics, 1996; revised 1997).

6. Collective knowledge or capability, including tacit elements maintained and transmitted by active use, is discussed by Richard Nelson and Sidney Winter, An Evolutionary Theory of Economic Change (Cambridge, Mass.: Harvard University Press, 1982).

7. Jonathan Temple and Paul Johnson's "Social Capability and Economic Development,'” Quarterly Journal of Economics 113, no. 3 (August 1998): 96590, which investigates the effect of measures of social development of the type studied by Irma Adelman and Cynthia T. Morris (Society, Politics and Economic Development [Baltimore: Johns Hopkins University Press, 1967]), bears a close relationship to our study, if one believes that their social indicators are appropriate measures of the "broad human capital" that we hypothesize to be associated with PID. (See also Moses Abromovitz, "Catching Up, Forging Ahead, and Falling Behind,' Journal of Economic History 46 [June 1986]: 385-406.) The differences between their approach and ours are $(a)$ that they provide no economic-historical framework to explain why social development differed among countries in the 1960s, and (b) that we use direct physical measures of PID 
rather than social development measures, which might be considered more "epiphenomenal" and which are in many cases rather subjective in character.

8. A more ideal measure would be the average population density of a country's regions, provinces, or other subnational units, weighted by regional population. Unfortunately, such detailed information is difficult to obtain for a large sample of countries.

9. Another potential problem is mechanization, which gives rise to lower man-to-land ratios at the industrialized end of the continuum. Fortunately, mechanization would have had next to no impact on farmer-to-land ratios in the developing countries that are the focus of our analysis.

10. Thus a referee (as well as Robert Wade, Brown University, in personal communication, 1997) argued that not irrigating may simply reflect not needing to irrigate. A measure that has an advantage over the irrigation share in this respect is the multiple cropping index, i.e., the average number of crops grown per year per parcel. This has been found to perform extremely well in a paper paralleling this study but in which the cross-sectional units are provinces in China, rather than countries (Ambar Narayan and Louis Putterman, "Pre-Industrial Development and Modern Economic Growth: Evidence from Regional Data for China' [Brown University, Department of Economics, 1998, photocopied]). Unfortunately, we did not find the index in the F.A.O. Yearbooks and other data sources we investigated, and thus we could not use it in this study.

11. Ross Levine and David Renelt, "A Sensitivity Analysis of CrossCountry Growth Regressions," American Economic Review 82 (September 1992): 942-63; Robert Barro, "Economic Growth in a Cross-Section of Countries," Quarterly Journal of Economics 106 (May 1991): 407-44; Roger Kormendi and Philip Meguire, "Macroeconomic Determinants of Growth: CrossCountry Evidence,' Journal of Monetary Economics 63 (September 1985): 141-63.

12. As will be noted again below, we do not posit any particular relationship between formal education and the types of human capital that one would expect to derive from the nature of the preindustrial economy. Thus, findings about the effects of formal education on growth have no direct bearing on the hypothesis that PID has affected growth through broad characteristics of the human-capital stock.

13. Robert Barro and Jong-Wha Lee, "Sources of Economic Growth," Carnegie-Rochester Conference Series on Public Policy 40 (June 1994): 1-46; Robert Barro, "Democracy and Growth," Journal of Economic Growth 1 (March 1996): 1-27; Roberto Perotti, "Growth, Income Distribution, and Democracy: What the Data Say," Journal of Economic Growth 1 (June 1996): 149-87.

14. Development economists have long argued that many economies operate with greatly reduced economic efficiency because government interventions, e.g., in banking, import controls, and foreign-exchange management led to artificially reduced capital and import costs, higher labor costs, and lower profitability of exports. The black market premium should be an accurate measure of one of these distortions, the degree of currency overvaluation, which is likely to be highly correlated with others. The purchasing power parity of investment goods, the variable favored by Perotti, seems less satisfactory because purchasing power parities tend to be systematically associated with levels of development for reasons that may have little to do with the kinds of price distortion in question here.

15. Food and Agriculture Organization of the United Nations, F.A.O. Production Yearbook (Rome: Food and Agriculture Organization of the United Nations, 1970, 1978). Data on total land area, arable land, and irrigated land in 
1960 were taken from the 1978 yearbook; data on agricultural population in 1960 were taken from the 1970 yearbook. The total population data for 1960 were taken from the data used by Barro and Lee.

16. Robert Summers and Alan Heston, "The Penn World Tables (Mark 5): An Expanded Set of International Comparisons, 1950-1988,' Quarterly Journal of Economics 106 (May 1991): 327-68.

17. Ibid.

18. Most of the estimates of $\beta_{1}$ are both negative and statistically significant, suggesting that the expected variance in data quality may in fact exist. However, checks of alternative estimates suggest that the qualitative nature of the results is affected little by whether or not the weights are used.

19. Since the four proxies are positively correlated, we cannot be confident of the signs of the estimated coefficients when more than one proxy is included. We therefore omit such estimates.

20. A country is included in the computations of this table if we have sufficient data to include it in at least one of the regression estimates shown in tables 2,3 , or 4 . See table A1.

21. Results for the larger sample of 48 countries are qualitatively similar, but the coefficient on GDP60 becomes significant at the .01 level, and that on BMP not significant at the .05 level. The insignificant negative coefficients on population growth for the 1960-90 period as a whole, both in this and the other columns of the table, are consistent with the positive coefficients for the 196075 subperiod and negative coefficients for the 1975-90 subperiod, shown in tables 2 and 3. Note that while our hypothesis stipulates that high population density at the outset of the industrial era would be associated with conditions favorable to modern economic growth, it involves no prediction regarding the effects of population growth after the commencement of the drive for industrialization.

22. Recall that 1960 data were used because these were the earliest we could obtain for a broad subsample of countries. The common use of data for the year 1960 both for the PID measures and for the initial GDP and education variables in the 1960-90 and 1960-75 estimates is strictly coincidental.

23. We also estimated, but do not show, a model in which all three individual PID variables appear simultaneously with the other variables. The $R^{2}$ for this model is .74 , suggesting that it explains more of the total variance, as well as of the variance unexplained by model 1 , than does the model adding the region dummies only. As mentioned earlier, however, it is difficult to interpret the individual PID coefficients, since the three variables are correlated. Although they pass an $F$-test for joint significance at the .001 level, only one of them, irrigation, shows a significant coefficient.

24. To provide points of comparison, we note that the $\beta$ coefficients for GDP60, Sec60, GPOP6090, INV6090, and BMP6090 in model 7 are -.18, $-.09,-.06, .32,-.19$.

25. A major gap in coverage is that of the former Communist countries.

26. Hong Kong, a British colony absorbed by China in 1997, is treated as a country in World Bank data up to this writing, by Summers and Heston, and in most of the cross-sectional growth studies referred to above.

27. Our main sample did not include South Korea because the growth rate of GDP per capita of that country in 1985-90 is not given in Barro and Lee. Also missing from that source are data for China. We filled in the missing growth rate for South Korea, using the World Bank's World Tables (published for the World Bank by Johns Hopkins University Press, Baltimore, 1992). Missing data for China were obtained by taking intermediate estimates from those offered by a variety of specialized sources, in consultation with Barry Naughton, University of California, San Diego. Details are provided in John Burkett, Cath- 
erine Humblet, Ambar Narayan, and Louis Putterman, "Appendix to Burkett, Humblet and Putterman,' unpublished paper (Brown University, 1998; hereafter cited as BHNP).

28. The one exception is the $1960-75$ period, for which the coefficient is insignificant (but still positive) in the sample that substitutes the former for the latter countries. Results are shown in BHNP.

29. William Easterly and Ross Levine, "Africa's Growth Tragedy: Policies and Ethnic Divisions,' Quarterly Journal of Economics 112 (November 1997): $1203-50$.

30. Societies nearer to the less intensive end of the PID spectrum would have tended to have had smaller units of social integration (e.g., tribes), more of which would thus be included in the boundaries of today's typically larger nation-states.

31. This is an ethnic heterogeneity index constructed by scholars in the then-Soviet Union, as well as the average of that index and of several nonSoviet indexes of ethnic heterogeneity.

32. Only the average ethnic heterogeneity index is significant. Both indices have significant coefficients of the predicted sign for 1960-90, but not for the subperiods, when PC1 is not included, for these samples. Sample sizes are 40, 55, and 46 for 1960-90, 1960-75, and 1975-90, respectively. Results for the 1960-90 period are included in BHNP. Results are similar when China and South Korea are substituted for Hong Kong and Singapore, as in table 6.

33. While life expectancy is a possible proxy for human-health capital, it is also an important measure of well-being and in that respect an outcome of economic performance. To what extent life expectancy or other physical quality of life or human-development measures might be determined by such underlying factors as initial income and legacies of premodern development versus government policies or other factors is an interesting question that we are unable to explore here. (We did some exploratory regressions on our sample and found that about $57 \%$ of the variance of life expectancy in 1960 within our sample appears to be explained by a constant term, GDP per capita in 1960, and the three PID measures.) For an exploration of the determinants of the physical quality of life, see John Burkett, "Systemic Influences on the Physical Quality of Life: A Bayesian Analysis of Cross-Sectional Data,' Journal of Comparative Economics 9 (June 1985): 145-63.

34. See BHNP.

35. Jeffrey Sachs and Andrew Warner, "Sources of Slow Growth in African Economies," working paper (Harvard Institute for International Development, March 1997). This version differs slightly from that published under the same title in the Journal of African Economics 6, no. 3 (December 1997): 33576.

36. For further details and a sample result, see BHNP.

37. These statements apply mainly to Western Europe. Comparable data for former Communist East and Central Europe are not provided in our sources.

38. In our 1997 paper (n. 5 above), we argue that where indigenous population densities were sufficiently low, as in North America and Australia, colonization and subsequent immigration led to substitution of the indigenous PID correlates by the human-capital profile associated with the PID level of the colonizers. We also point out that as the location of the first industrial revolution was probably not predictable on the basis of population density only, PID as we measure it is not a sufficient condition for industrialization. This opens up complex issues for further discussion.

39. The basic result for the sample including both OECD and non-OECD countries is included in BHNP. 
40. Our hypothesis with respect to human capital may be viewed as similar to the "social capability" concept that Temple and Johnson (n. 7 above; in research that came to our attention after completing this project) take from Abromovitz (n. 7 above) and other earlier writers. Perhaps the main difference between their approach and ours is that whereas they take "social capability" to be an unexplained variable that is measured directly by an index based on such factors as "extent of dualism," "extent of social mobility," and "degree of modernization of outlook," we carry our analysis back one step to the long historical perspective of economic anthropologists and others, and our tests proceed on the assumption that direct measures of production-system intensity may be superior to measures of consequences, some of which are unavoidably subjective. The relationship between the PID and the social capability concepts deserves investigation in future work.

41. Indeed, formal education fails to show systematic impact in the results obtained here, perhaps due to difficulties of measurement. See also Lant Pritchett, 'Where Has All the Education Gone?' unpublished paper (World Bank, Washington, D.C., 1995) and sources cited therein. 
This content downloaded from 131.128.70.27 on Tue, 19 Mar 2013 11:26:58 AM All use subject to JSTOR Terms and Conditions 